\title{
Development of a Sustainable UHPC Deck for Movable Bridges
}

Fatmir Menkulasi PhD, P.E.: Assistant Professor, Department of Civil Engineering, Louisiana Tech University, Ruston, LA

Jacob Parker P.E.: Structural Engineer, Stantec, Baton Rouge, LA

Carlos Montes PhD: Research Assistant Professor, Institute of Micromanufacturing, Louisiana Tech University, Ruston, LA

Hadi Baghi PhD: Post-doctoral Researcher, Department of Civil Engineering, Louisiana Tech University, Ruston, LA

Jean-Paul Sandrock: Undergraduate Research Assistant, Department of Civil Engineering, Louisiana Tech University, Ruston, LA

Sergio Gomez: Research Associate, Institute of Micromanufacturing, Louisiana Tech University, Ruston, LA

\begin{abstract}
Louisiana has approximately 160 movable bridges, mostly in the southern part of the state. This places Louisiana among the states with the highest inventory of movable bridges in the nation. The typical deck systems in these movable bridges are steel grids. On average these decks weigh approximately $20 \mathrm{lb} / \mathrm{ft}^{2}\left(0.96 \mathrm{kN} / \mathrm{m}^{2}\right)$. Records show that steel grids have had maintenance issues. The proximity of these exposed steel systems to humid environments leads to rapid deterioration. As a result, decks become loose, causing extreme noise. Furthermore, bridges close to residential areas often receive complaints from residents about noise levels resulting from vehicles crossing over the steel grids. An alternative UHPC/HPC bridge deck system is proposed. This system consists of precast waffle slab deck panels that are as light as the steel grid decks so that the load demand on the mechanical system is not increased. The waffle slab deck panels are reinforced with $\mathrm{MMFX}_{2}$ bars and a two-way carbon fiber mesh. Several tests were conducted on a commercial UHPC formulation to characterize the short term behavior in terms of compressive strength, tensile strength, modulus of elasticity and unit weight. These parameters were then used in the design of the precast deck panels to determine the necessary waffle slab panel geometry to meet performance demands.
\end{abstract}

Keywords: UHPC/HPC, waffle slab, movable bridge deck. 


\section{Introduction}

Louisiana has approximately 160 movable bridges, mostly in the southern part of the state. This places Louisiana among the states with the highest inventory of movable bridges in the nation. These transportation arteries are important for the economic well-being of the state, as well as for the safety of the inhabitants in hurricane vulnerable regions during evacuations. Most of the movable bridges in Louisiana are either swing-span or lift-bridge type structures. Very few movable steel bridges are of the bascule type. The typical deck systems in these movable bridges are steel grids. These decks are light and easily replaceable. However, records show that steel gratings have had maintenance issues. The proximity of these exposed steel systems to humid environments leads to rapid deterioration. As a result, decks become loose, causing extreme noise. Furthermore, bridges close to residential areas often receive complaints from residents about noise levels resulting from vehicles crossing over the steel grids. These problems are aggravated by trapping foreign debris throughout the deck grids. The Louisiana Department of Transportation and Development (LADOTD) has an interest in using concrete decks on movable bridges. The weight of conventional concrete decks will have a negative impact on the mechanical system be it through vertical lifting or horizontal swaying of the deck. Accordingly, a light UHPC/HPC concrete deck is proposed as an alternative to steel grid decking.

\section{Background}

Decks in movable bridges have been traditionally constructed with open steel grids supported by steel stringers at typically $4 \mathrm{ft}(1220 \mathrm{~mm})$ on center. On average these decks weigh less than 25 $\mathrm{lb} / \mathrm{ft}^{2}\left(1.2 \mathrm{kN} / \mathrm{m}^{2}\right)$; while some others can weigh as little as $14 \mathrm{lb} / \mathrm{ft}^{2}\left(0.7 \mathrm{kN} / \mathrm{m}^{2}\right)$ (Mirmiran et al. 2009). This deck system is attractive because it is light weight, the panels are prefabricated and they are easy to install. Also, deck crowning, scuppers, and drains are not required, since rain water drains through the openings in the deck (Mirmiran et al. 2009). The light weight helps with imposing as little of a demand as possible on the mechanical system.

Open steel grid decks typically consist of either diagonal or rectangular grids (Figure 1 (a), (b)) and were first introduced in the 1920s (Gase accessed 2016). Other types of light weight bridge decks that have been used on non-movable bridges include full depth concrete filled grids (Figure 1 (c)), partial depth concrete filled grids (Figure 1 (d)) and Exodermic ${ }^{\mathrm{TM}}$ decks (Figure 1 (e)). The full depth grid was introduced in the 1930s to speed up construction in large bridge projects (Gase accessed 2016). The partially filled grid system was first used in the 1950s to further reduce weight by eliminating concrete in the bottom tension zone (Gase accessed 2016). The Exodermic ${ }^{\mathrm{TM}}$ deck was developed in the 1980s and it evolved from the concrete filled grid decks by optimizing the material properties where they best fit (Gase accessed 2016). Although all of the aforementioned lightweight concrete filled steel grid decks are useful for many bridge types, they do not provide a competitive alternative for movable bridges because of their weight. The weight range for these type of decks varies from $60 \mathrm{lbs} / \mathrm{ft}^{2}$ to $110 \mathrm{lbs} / \mathrm{ft}^{2}\left(2.9 \mathrm{kN} / \mathrm{m}^{2}\right.$ to $\left.5.3 \mathrm{kN} / \mathrm{m}^{2}\right)$. Garcia (2007) and Aaleti et al. (2013) investigated an UHPC waffle deck for non-movable bridges, which was later implemented in Iowa as part of a deck replacement project. Although the weight of this deck system exceeds the weight limit for movable bridge decks, it provided a good starting point for the development of the waffle deck system described later in this paper.

Florida Department of Transportation (FDOT) in collaboration with URS Corporation identified several potential alternative lightweight solid deck systems to replace steel open grid decks on typical Florida bascule bridges (Mirmiran et al. 2009; Mirmiran et al. 2012; and Phillips 
2014). These deck systems include a sandwich plate system (SPS) (Figure 2 (a)), an FRP composite deck (Figure 2 (b)), an aluminum orthotropic deck (Figure 2 (c)), a prismatic concrete deck with FRP tubes (Figure 2 (d)), a non-prismatic concrete deck with FRP tubes (Figure 2 (e)), a FRP deck (Figure 2 (f)), and a waffle slab UHPC deck (Figure 3) .

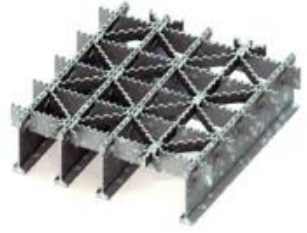

(a)

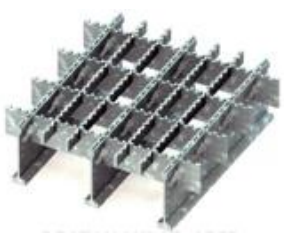

(b)

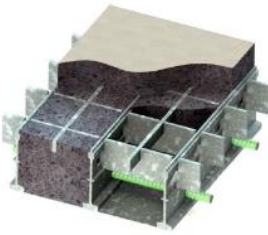

(c)

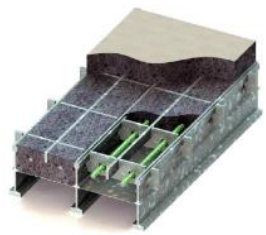

(d)

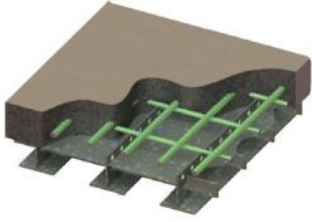

(e)

Figure 1. Prefabricated steel grid bridge decks, (a) diagonal grid, (b) rectangular grid, (c) full depth concrete filled grid, (d) partial depth concrete filled grid, e) Exodermic ${ }^{\mathrm{TM}}$ deck (reprinted from Gase accessed 2016)

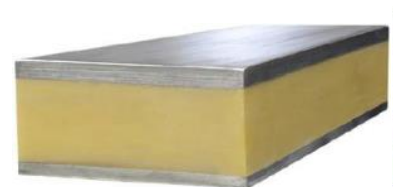

(a)

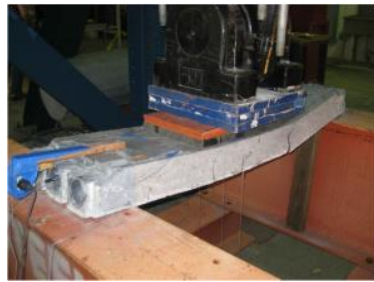

(d)

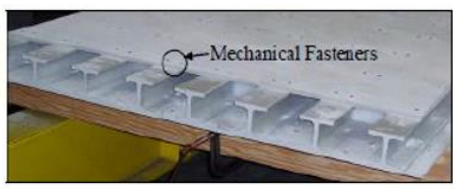

(b)

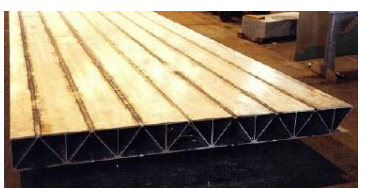

(c)

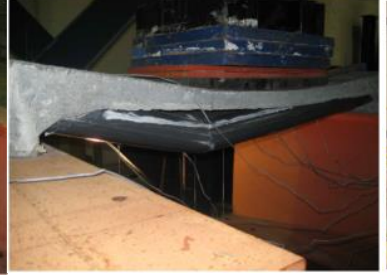

(e)

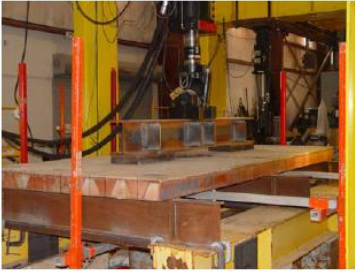

(f)

Figure 2. Alternative lightweight solid deck systems: (a) Sandwich plate system, (b) FRP composite deck, (c) Aluminum orthotropic deck, (d) Prismatic concrete deck with FRP tubes, (e) Non-prismatic concrete deck with FRP tubes (f) FRP deck (reprinted from Mirmiran et al. 2009; 2012)
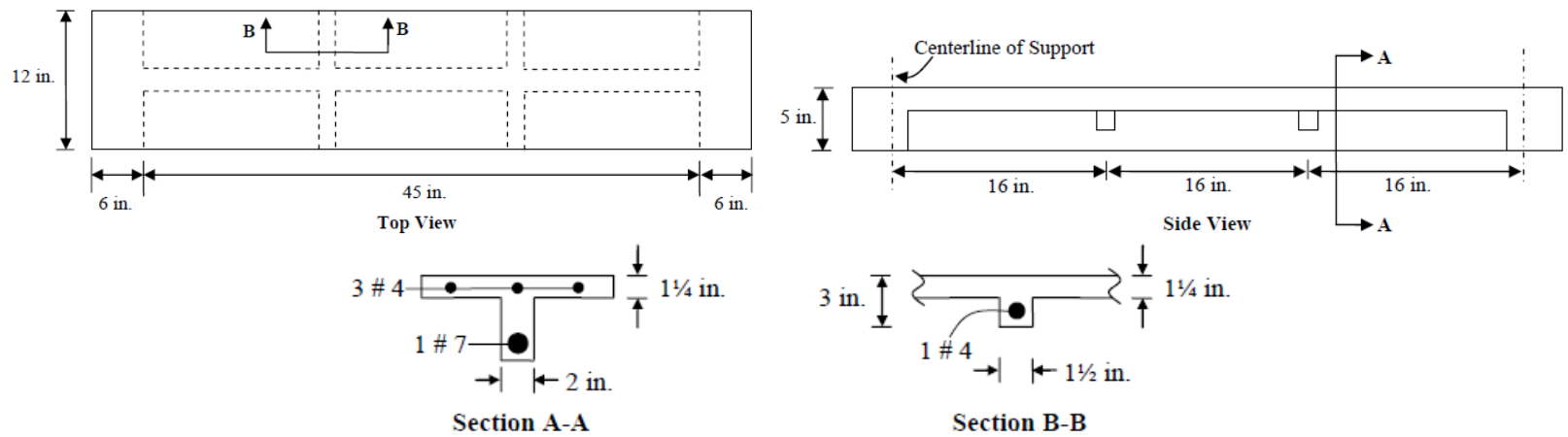

Figure 3. Waffle slab UHPC deck system with MMFX 2 rebars (reprinted from Mirmiran et al. 2012) $(1 \mathrm{in}=25.4 \mathrm{~mm})($ No. $4($ US $)=$ No. $13($ SI $)$, No. $7($ US $)=$ No. $22($ SI $)$

The sandwich plate system and the FRP composite systems are vulnerable to delamination, debonding and cracking of wearing surface. The aluminum orthotropic deck is a patented product, requires expansion joints, requires periodic replacement of the wearing surface, and it requires galvanic corrosion mitigation, as well as the potential use of blind-type fasteners (Mirmiran et al. 2009). The UHPC deck with FRP tubes was not investigated with respect to the performance of panel to stringer connections, panel to panel connections, and fatigue performance of the system. 
The deflection of the FRP deck system under service load significantly exceeded the deflection limit suggested by AASHTO LRFD (2014).

Accordingly, a modified version of the waffle slab UHPC deck is proposed for investigation in this study because: 1) it can meet the limitations on weight, 2) it uses a two-way carbon fiber mesh and $\mathrm{MMFX}_{2}$ bars which are corrosion resistant and high strength, 3) uses panel to panel and panel to stringer connections that are intended to emulate monolithic action, and 4) it includes a chip seal surface coating to provide skid resistance. The replacement of steel grids with a concrete deck that acts compositely with the steel stringers is expected to enhance the performance of the overall superstructure with respect to strength and deflections.

\section{Compilation of Louisiana's current moveable bridge deck system details}

The mechanical systems of moveable bridges are highly sensitive. As a result, any decking system used to replace or rehabilitate the existing steel grid decking should match the weight of the existing system such that the mechanical system operates as designed.

A list of movable bridges that utilize steel grid decking was obtained from LADOTD. The bridge plans including as-built drawings and shop drawings were searched to collect all relevant information such as: panel thickness, panel weight, panel length, maximum cantilever length, span range and stringer size. The bridge plans for a total of 17 bridges were investigated. The minimum and maximum deck thickness were 5.075 in. $(130 \mathrm{~mm})$ and $5.885 \mathrm{in}$. (150 mm), respectively. There was a minimum deck weight requirement only for two bridges $\left(16 \mathrm{psf}\left(0.8 \mathrm{kN} / \mathrm{m}^{2}\right)\right.$ and 17.5 psf $\left.\left(0.85 \mathrm{kN} / \mathrm{m}^{2}\right)\right)$. The maximum deck weight limitation based on stringer reactions was typically $20 \mathrm{psf}\left(0.96 \mathrm{kN} / \mathrm{m}^{2}\right)$ with the exception of one bridge for which this limitation was $18 \mathrm{psf}(0.9$ $\left.\mathrm{kN} / \mathrm{m}^{2}\right)$. The most common girder type was W16×36 (W410×54). Stringer spacing varied from 44 in. to $56 \mathrm{in}$ (1120 $\mathrm{mm}$ to $1425 \mathrm{~mm}$ ), although most bridges had stringer spacing less than 50 in (1270 mm).

Based on the collected information the following recommendations are made with the respect to the UHPC deck panels (Table 1). The panel thickness is recommended to be $5.1875 \mathrm{in}$. $(132 \mathrm{~mm})$ to be consistent with the predominant existing grid deck thicknesses. The maximum panel weight should be limited to $20 \mathrm{psf}\left(0.96 \mathrm{kN} / \mathrm{m}^{2}\right)$. The panel length should be such that it covers at least three spans to take advantage of continuity and the span length should be taken equal to 50 in $(1270 \mathrm{~mm})$. The stringer size should be taken as W16×36 (W410×54).

Table 1. Findings and recommendations for UHPC deck panel

\begin{tabular}{lll}
\hline \multicolumn{2}{c}{ Findings/Recommendations } & \multicolumn{1}{c}{ Reason/Comment } \\
\hline Panel Thickness, in. $(\mathrm{mm})$ & $5.1875(132)$ & To be consistent with existing grid deck \\
Panel weight, psf $\left(\mathrm{kN} / \mathrm{m}^{2}\right)$ & $20(0.96)$ & Calculated based on stringer reactions \\
Panel length & TBD & Set by testing apparatus and costs, not less than 3 bays \\
Span range, in. $(\mathrm{mm})$ & $44-56(1120-1420)$ & Either simple span made cont. or min. of three spans \\
Stringer & $\mathrm{W} 16 \times 36(\mathrm{~W} 410 \times 54)$ & Most common stringer \\
\hline
\end{tabular}

\section{Proposed Precast Deck System}

The proposed deck system is illustrated in Figure 4. The steel stringers are spaced at 50 in. (1270 $\mathrm{mm})$ on center. The width of a single precast panel is $48 \mathrm{in.}(1220 \mathrm{~mm})$. The overall depth of the deck panels is $5-3 / 16$ in $(132 \mathrm{~mm})$. The thickness of the flange is $7 / 8 \mathrm{in}(23 \mathrm{~mm})$. The width of the transverse ribs, which will act as T-beams to support the superimposed loads varies, and it is 2 in. $(51 \mathrm{~mm})$ at the bottom and it tapers down to $7 / 8$ in $(23 \mathrm{~mm})$ (Detail A). The width of end ribs is 
constant and is equal to $1.25 \mathrm{in}(32 \mathrm{~mm})$. There are six partial depth longitudinal ribs, which help distribute loads to the adjacent panels. The dimensions of the partial depth ribs are 7/8 in. (23 $\mathrm{mm}$ ) wide and 0.75 in. (19 mm) deep (Detail D). There is a distance of 15/16 in. (24 mm) between the end of the panels and the centerline of the stringers to allow for the placement of a cast-in-place UHPC/HPC diaphragm. Strips of foam boards can be glued at the end of the precast panels to serve as pour stops for the CIP concrete diaphragms. The spacing of the transverse ribs is 16 in. $(407 \mathrm{~mm})$ center to center for the interior ribs and $16 \mathrm{in} .(407 \mathrm{~mm})$ from the center of the interior rib to the outside face of the exterior rib. The weight of a single panel considering the cast in place UHPC/HPC diaphragm is $19.94 \mathrm{psf}\left(0.96 \mathrm{kN} / \mathrm{m}^{2}\right)$ and was calculated using a measured unit weight of $156 \mathrm{pcf}\left(2500 \mathrm{~kg} / \mathrm{m}^{3}\right)$ for Ductal (commercial UHPC/HPC formulation). Ductal was provided by Lafarge North America. The panel weight was calculated by ignoring the presence of the reinforcing bars and mesh. Alternative concrete mixes and reinforcing bars will be considered in the next phase of the project. For each set of materials various deck panel configurations will be developed and panel weight calculations will be refined to include the presence of reinforcing. Each interior transverse rib is reinforced with a No. 8 (25.4 mm) $\mathrm{MMFX}_{2}$ bar and each exterior rib is reinforced with a No. 6 bar at the bottom. MMFX $_{2}$ bars are corrosion resistant reinforcing bars provided by MMFX Technologies. The partial depth longitudinal ribs are reinforced with a No.4 $\mathrm{MMFX}_{2}(12.7 \mathrm{~mm})$ bar to help distribute wheel loads in the longitudinal direction. $\mathrm{MMFX}_{2}$ bars may be replaced with either carbon fiber or glass fiber reinforced polymer bars (V-rod) if the performance of the panel is proved satisfactory.

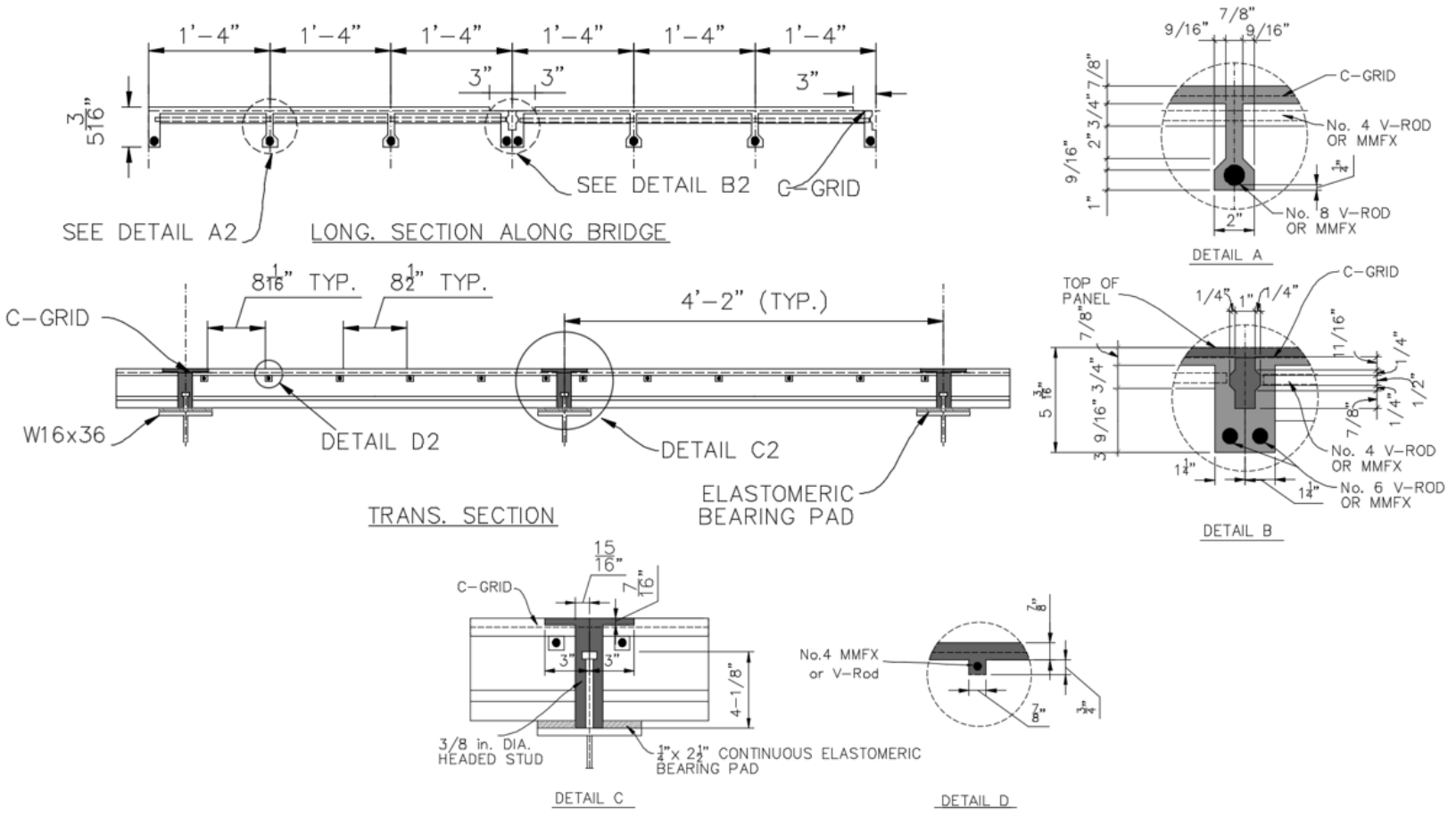

Figure 4. Details of the proposed deck system $(1$ in $=25.4 \mathrm{~mm})($ No. 4, 6, 8 (US) $=$ No. 13, 19, 25 (SI)

Flange reinforcing consists of a two-way non-corrosive carbon fiber grid (C-grid) developed by Chomarat North America and has a tensile strength over four times higher than steel by weight. C-grid is an epoxy-coated composite grid made with cross-laid and superimposed carbon fiber. The $\mathrm{C}$-grid helps distribute loads in the longitudinal direction, serves as negative moment reinforcing in the transverse direction and controls crack widths. The $\mathrm{C}$-grid was used as 
top flange reinforcing by Mirmiran and Ghasemi (2016) during deck panel testing performed in Florida. Figure 4 Detail B illustrates the proposed panel to panel connection, which features female type shear keys, and a site cast UHPC/HPC fill. It is expected that this detail will emulate monolithic action and provide adequate shear and moment transfer. All the interfaces between precast and cast-in-place UHPC/VHPC in the proposed connections may be sandblasted and kept moist at surface saturated dry conditions to enhance bond. Detail $\mathrm{C}$ illustrates the panel to stringer connection and features headed studs and a cast-in-place UHPC/HPC diaphragm. A leveling system at the stringer supports will need to be employed for the precast deck panels to provide drainage given that the traditional steel grid system relies on the openings for drainage purposes. Additionally, a chip seal surface, which weighs less than $0.33 \mathrm{lb} / \mathrm{ft}^{2}$ will be applied on the top of the deck to increase skid resistance. Also, the top of the precast panels may receive a broom finish to further enhance traction.

The proposed system will offer a solid riding surface, which is expected to improve ride quality compared to steel grid decks. Additionally, the proposed panel to panel connections and panel to stringer connection are intended to emulate monolithic construction and address the problems associated with deterioration and noise manifested in steel grid decks. Also, the high durability of UHPC/HPC combined with corrosion resistant $\mathrm{MMFX}_{2}$ bars at the bottom and a twoway carbon fiber mesh at the top is expected to address the durability problems present in steel grid decks.

\section{Deck Panel Design}

A full design of a typical deck panel for flexure and shear (one-way and two-way) using AASHTO's strip method was performed. In this design only a single deck panel simply supported along the stringers was considered. The UHPC/HPC material used in these calculations is the commercial formulation Ductal. The design compressive strength, $\mathrm{f}_{\mathrm{c}}$, the tensile strength $\mathrm{f}_{\mathrm{t}}$, and the modulus of elasticity E, were based on tested values at 28 days. Reinforcing bars in the interior ribs were taken as No. $8 \mathrm{MMFX}_{2}$ bars. The material properties used in deck panel design are provided in Table 2 .

Table 2. Material properties used in UHPC deck panel design (1 ksi = 6.9 MPa, $1 \mathrm{in}=25.4 \mathrm{~mm}, 1 \mathrm{lb}=0.45 \mathrm{~kg})$

\begin{tabular}{ccc}
\hline Concrete $(28$ days) $($ Ductal) & & Comments \\
\hline Compressive strength $\left(\mathrm{f}^{\prime}{ }_{\mathrm{c}}\right)(\mathrm{ksi})$ & 20.73 & Measured \\
Tensile Strength $\left(\mathrm{f}_{\mathrm{t}}\right)(\mathrm{ksi})$ & 1.62 & Measured \\
Modulus of Elasticity $(\mathrm{E})(\mathrm{ksi})$ & 8167 & Measured \\
Unit Weight $\left(\gamma_{\text {Ductal }}\right)\left(\mathrm{lbs}_{\mathrm{ft}}{ }^{3}\right)$ & 156 & Measured \\
Peak strain $\left(\varepsilon_{\text {peakDuctal }}\right)(\mathrm{in} / \mathrm{in})$ & 0.0032 & Measured \\
\hline Steel $\left.(\mathbf{M M X})_{2}\right)$ & & Comments \\
\hline Yield stress $\left(\mathrm{f}_{\mathrm{y}}\right)(\mathrm{ksi})$ & 120 & From literature \\
Modulus of Elasticity $(\mathrm{E})(\mathrm{ksi})$ & 25714 & From literature \\
\hline
\end{tabular}

The strip method resulted in effective strip widths that were larger than the width of the panel. As a result it was conservatively assumed that one panel will support its self-weight as well as the load from one HL-93 truck wheel (16 kips (110 MPa)). Additionally, it was assumed that the load supported by an interior rib is equal to $1 / 2$ of the total wheel load. Three wheel load positions were used during design: 1) wheel load at mid-span to maximize bending moment ( $\left.\mathrm{M}_{\mathrm{udemand}}\right), 2$ ) wheel load near the support to maximize beam shear ( $\left.\mathrm{V}_{\text {udemand(one-way) }}\right)$, and 3) wheel load centered between the transverse ribs and also positioned such that it includes the minimum 
number of longitudinal ribs to represent the worst case from a punching shear perspective

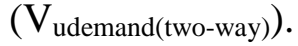

The stress strain compression curve for Ductal obtained from material testing exhibited primarily a linear elastic behavior (Figure 5 (a)). As a result, when designing for flexure the shape of the concrete compression block was idealized as a triangular prism. The contribution the tensile strength of Ductal was taken into account by assuming the tensile stress distribution below the neutral axis to be a rectangle whose value is equal to the tensile strength of Ductal at 28 days. Compression and tension test cylinders were moist cured until the day they were tested. The stress strain relationship for the reinforcing steel $\left(\mathrm{MMFX}_{2}\right.$ Grade $120 \mathrm{ksi}(827 \mathrm{MPa})$ ) was idealized as elastic perfectly plastic. This is illustrated by the dashed line in Figure 5 (b). Because the analysis employed was a beam line analysis based on assumed distribution factors and a simply supported span configuration, the contribution of the $\mathrm{C}$-grid was ignored. As stated earlier, the function of the $\mathrm{C}$-grid is primarily to help distribute loads in the longitudinal direction, serve as negative moment reinforcing and control crack widths. The design for flexure revealed that the neutral axis fell in the flange and the ratio between the factored moment demand ( $\left.\mathrm{M}_{\text {udemand }}\right)$ and supply $\left(\phi \mathrm{M}_{\mathrm{n}}\right)$ was 0.65 . Accordingly, bending is not expected to govern the design of the panels. However, a more accurate estimate of the moment demand will be performed when live load distribution factors (LLDFs) for moment are obtained analytically, using finite element analysis (FEA), and experimentally, using deck panel testing.

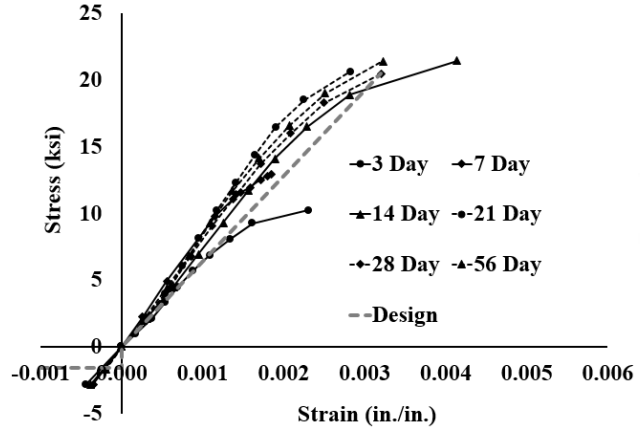

(a)

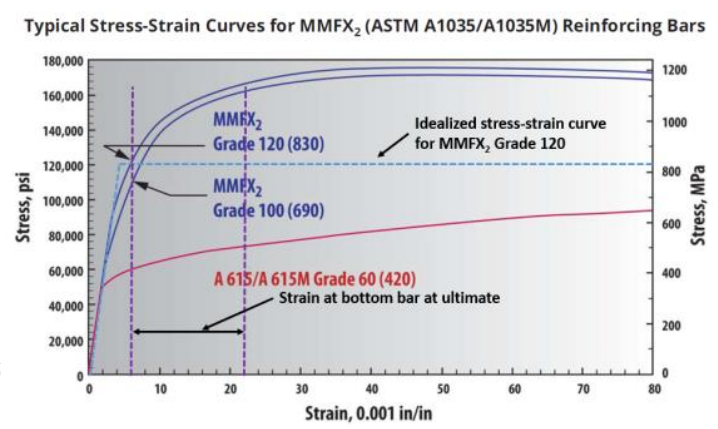

(b)

Figure 5. Stress strain curves, (a) Ductal, (b) MMFX 2 (Adopted from MMFX Technologies) (1ksi =6.9MPa)

Three types of sensitivity analyses were performed to investigate the effect of the compressive and tensile strength of concrete, as well as the influence of the yield stress of reinforcing steel on the flexural strength of the UHPC deck panel. In the first, the design compressive strength was varied from $10 \mathrm{ksi}$ to $22 \mathrm{ksi}$ (69 MPa to $151 \mathrm{MPa}$ ), and in the second, the design tensile strength was varied from 0 to $2.4 \mathrm{ksi}(16.5 \mathrm{MPa})$. The results are illustrated in Figure 6 (a) and (b). When the design compressive strength was varied, the flexural strength varied from $28 \mathrm{ft}$-kips $(38 \mathrm{kN} . \mathrm{m})$ to $31 \mathrm{ft}-k i p s(42 \mathrm{kN} . \mathrm{m})$. When the tensile strength was varied, the flexural strength varied from $28 \mathrm{ft}-\mathrm{kips}(38 \mathrm{kN} . \mathrm{m})$ to $31 \mathrm{ft}-\mathrm{kips}(42 \mathrm{kN} . \mathrm{m})$. Neither the compressive strength nor the tensile strength had a significant influence on the flexural strength of the deck panel. Finally, the reinforcing yield stress was varied from $60 \mathrm{ksi}$ to $120 \mathrm{ksi}$ (413 MPa to 827 $\mathrm{MPa})$. The results are provided in Figure 6 (c). The flexural strength varied from $17 \mathrm{ft}$-kips $(23$ kN.m) to $30 \mathrm{ft}$-kips (40 kN.m). The yield stress of the reinforcing had a significant effect on the flexural strength of the UHPC deck panel. The tensile strains in the reinforcing steel during all sensitivity analyses described above varied from 0.006 to 0.04 as illustrated in Figure 5 (b). 

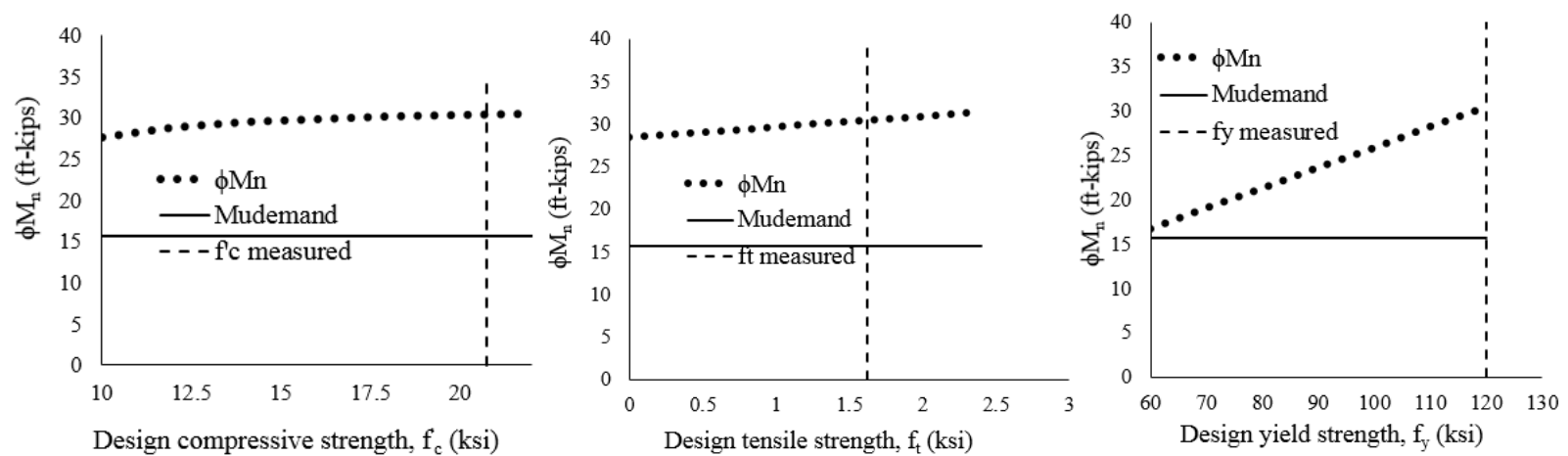

Figure 6. (a) Influence of $f^{\prime}$ c on flexural strength, (b) Influence of $f_{t}$ on flexural strength, (c) Influence of $f_{y}$ on flexural strength $(1 \mathrm{ksi}=6.9 \mathrm{MPa}, 1 \mathrm{ft}-\mathrm{kips}=1.4 \mathrm{kN} . \mathrm{m})$

The ratio between one-way shear demand $\left(\mathrm{V}_{\text {udemand (one-way) }}\right)$ and supply $\left(\phi \mathrm{V}_{\mathrm{n}}\right)$ was 0.82 . One-way shear capacity was estimated based on an approach that was adopted after the work performed by Baby et al. (2010). The proposed approach assumes that both the webs and the flange contribute to the shear capacity of the deck panel. Shear resistance was calculated as the resistance provided by concrete plus the resistance provided by fibers. The resistance provided by fibers was estimated to be approximately four times the resistance provided by concrete. Accordingly, the presence of fibers is essential in resisting shear forces. The resistance provided by fibers is a function of the concrete post-cracking tensile strength. Accordingly, the amount of fibers present in the mix is indirectly accounted for in terms of the post cracking tensile strength. In this formulation it is assumed that the higher the percentage of fibers, the higher the post cracking strength of concrete.

Two types of sensitivity analyses were performed to investigate the influence of the concrete compressive and tensile strength on the one-way shear strength of the UHPC deck panel, In the first the compressive strength at 28 days was varied from $10 \mathrm{ksi}$ (69 MPa) to $22 \mathrm{ksi}(152$ $\mathrm{MPa}$ ) (Figure 7 (a)). The influence of the concrete compressive strength on the one-way shear strength of the panel was not significant. The shear strength varied from 53 kips (365 MPa) to 56 kips (386 MPa). The one-way shear demand was calculated such that the wheel load was placed at a distance $d$ form the edge of the stringer flange, where $d$ is the effective depth of longitudinal reinforcing. In the second type of sensitivity analyses all design values were kept constant with the exception of the post cracking tensile strength, which was varied from 0 to $2.4 \mathrm{ksi}$ (16 MPa). The results are illustrated in Figure 7 (b). The post cracking tensile strength has a significant effect on the one-way shear strength of the UHPC deck panel. The shear strength values varied from 11.2 kips $(50 \mathrm{kN})$ to $77.5 \mathrm{kips}(345 \mathrm{kN})$. The shear demand is plotted in the same graph so that it can be compared to the shear strength. Also, the measured post-cracking tensile strength of Ductal is indicated with the dashed vertical line. In this case the post cracking tensile strength of ductal was conservatively taken equal to the load that caused the first crack during the splitting tensile strength tests.

The ratio between the two-way shear demand $\left(\mathrm{V}_{\text {udemand(two-way) }}\right)$ and supply $\left(\phi \mathrm{V}_{\mathrm{n}}\right)$ was 0.73 . Punching shear capacity was calculated based on recommendations by Harris and Wollman (2003). The tensile strength of concrete as determined from splitting tensile tests is a key parameter in the estimation of the punching shear capacity. A sensitivity analysis was performed to investigate the influence of the tensile strength of concrete on the two-way shear strength of the precast panel. The tensile strength was varied from 0 to $2.4 \mathrm{ksi}(16 \mathrm{MPa})$. The results are provided in Figure 7 (c). The two-way shear strength varied from 0 to 75.2 kips $(335 \mathrm{kN})$. The tensile 
strength has a significant influence on the two-way shear strength of the UHPC deck panel. The two-way shear demand was estimated as the wheel load (16 kips $(71 \mathrm{kN})$ ) times the live load factor (1.75) times the impact factor (1.33). This results in a demand equal to 37.24 kips $(166 \mathrm{kN})$.

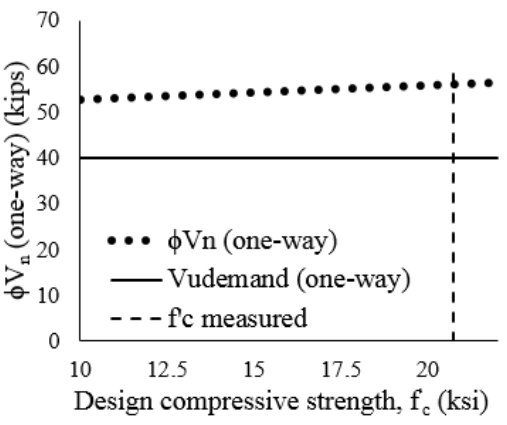

(a)

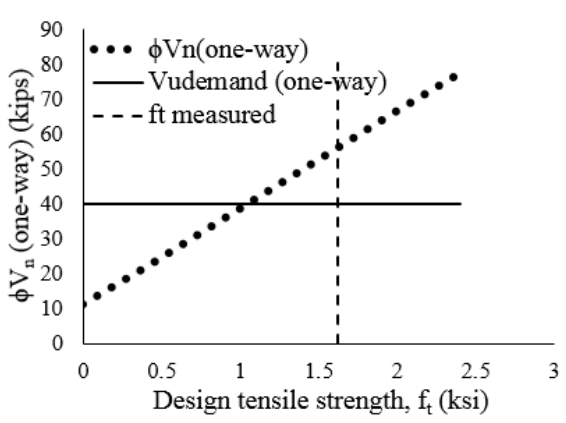

(b)

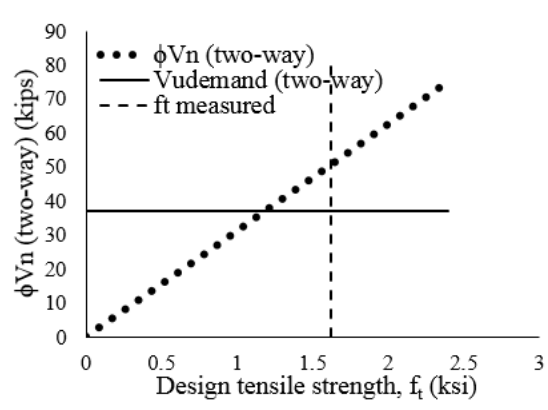

(c)

Figure 7. Influence of a) compressive strength on the one-way shear strength, b) tensile strength on the oneway shear strength, c) tensile strength on the two-way shear strength $(1 \mathrm{ksi}=6.9 \mathrm{MPa}, 1 \mathrm{kip}=4.4 \mathrm{kN})$

\section{Conclusions}

The development of an UHPC/HPC deck system for movable bridges was presented. The primary challenge in the development of this deck system was the limitation on the weight of the deck. The deck features state of the art concrete and reinforcing steel materials.

A preliminary design of a deck panel was conducted based on several assumptions to create a general idea about the relationship between load demand and capacity. AASHTO strip method was used to determine what portion of the deck can be used to resist HL-93 wheel loads. Additionally, it was assumed that the load supported by an interior rib is equal to $1 / 2$ of the total wheel load. These assumptions will be verified using 3D finite element analyses and physical tests in the upcoming phases of the project. It was concluded that the strength of the panel will likely be governed by shear rather than flexure. The one-way shear capacity was estimated based on an approach that was adopted after the work performed by Baby et al. (2010). The two-way shear strength of the panels was estimated based on the recommendations of Harris and Wollmann (2005). The actual mode of failure and the validity of the analytical models will be verified during the experimental phase of the project.

The tensile strength of the concrete is an essential property for the proposed deck system. The one-way and two-way shear models used in the design of the deck panel are highly influenced by the tensile strength of concrete. The compressive strength of concrete did not significantly affect the flexure, one-way shear, or two-way shear strength of the deck panel. The next phases of the project include investigating four additional concrete mixes with the purpose of identifying the mix that offers the best combination of performance and economy. Also, parametric studies will be conducted to investigate the influence of continuity, and various types of reinforcing bars. Additionally, linear and nonlinear finite element analyses as well as physical testing of panels will be conducted to investigate the validity of the assumptions made during the design of the deck panels. 


\section{References}

AASHTO LRFD Bridge Design Specifications, 7th Edition, Washington, DC, 2014

Aaleti, S., Petersen, B., and Sritharan, S., "Design Guide for Precast UHPC Waffle Deck Panel System, Including Connections", FHWA, U.S. Department of Transportation, Report No.

FHWA-HIF-13-032, Washington DC, 2013.

Baby, F., Billo, J., Renaud, J.C., Massotte, C., Marchand, P., Toutlemonde, F., Simon, A., Lussou, P., "Shear Resistance of Ultra High Performance Fibre Reinforced Concrete IBeams,"Proceedings of the 7th International Conference on Fracture Mechanics of Concrete and Concrete Structures, Jeju, Korea, May 2010, pp. 1,411-1,417.

Garcia, H.M., "Analysis of an Ultra-High Performance Concrete Two-Way Ribbed Bridge Deck Slab", FHWA, U.S. Department of Transportation, Report No. FHWA-HRT-07-056, Office of Infrastructure Research and Development Federal Highway Administration, McLean, VA, 2007.

Gase, P., M.,'Prefabricated Steel Grid Bridge Decks", Available at https://www.dot.state.oh.us/engineering/OTEC/2008\%20Presentations/55C.pdf [Cited January 23, 2016]

Harris, D.K. and Roberts-Wollmann, C.L., "Characterization of the Punching Shear Capacity of Thin Ultra-High Performance Concrete Slabs," Virginia Transportation Research Council, Report No. VTRC 05-CR26, Richmond, VA, 2005.

Mirmiran, A., Ghasemi, S., "Lightweight Solid Decks for Movable Bridges - Phase II", Final Report, Florida Department of Transportation Research Center, FDOT Contract No. BDV29977-11, January, 2016.

Mirmiran, A., Saleem, M., A., Mackie, K., Xia, J., “Alternatives to steel grid decks” Draft Final Report, Florida Department of Transportation Research Center, FDOT Contract No. BD015RPWO\#22, December, 2009.

Mirmiran, A., Saleem, M., A., Mackie, K., Xia, J., "Alternatives to steel grid decks - Phase II”, Final Report, Florida Department of Transportation Research Center, FDOT Contract No. BDK80 977-06, September 30, 2012.

Phillips, J., "Bascule Bridge Lightweight Solid Deck Retrofit Research Project", Florida Department of Transportation, Project Status Report, June 23, 2014. 